\title{
Retraction Note to: Dysfunction of nitric oxide synthases as a cause and therapeutic target in delayed cerebral vasospasm after SAH
}

R.M. Pluta

\section{Retraction Note to:}

Chapter "Dysfunction of nitric oxide synthases as a cause and therapeutic target in delayed cerebral vasospasm after SAH" in: T. Kırış__et al. (eds), Cerebral Vasospasm, Springer-Verlag/Wein https://doi.org/10.1007/978-3-211-75718-5_28

The author has retracted this article [1] because it has been previously published by the same author [2]. This article is therefore redundant. The author agrees to this retraction.

1. Pluta R.M. (2008) Dysfunction of nitric oxide synthases as a cause and therapeutic target in delayed cerebral vasospasm after SAH. In: Kırı̧ Zhang J.H. (eds) Cerebral Vasospasm. Acta Neurochirurgica Supplementum, vol 104. Springer, Vienna

2. Ryszard M. Pluta (2006) Dysfunction of nitric oxide synthases as a cause and therapeutic target in delayed cerebral vasospasm after SAH, Neurological Research, 28:7, 730-737.

The retracted version of this chapter can be found at https://doi.org/10.1007/978-3-211-75718-5_28

(C) Springer-Verlag/Wein, 2020

T. Kırış (eds.), Cerebral Vasospasm, https://doi.org/10.1007/978-3-211-75718-5_93 